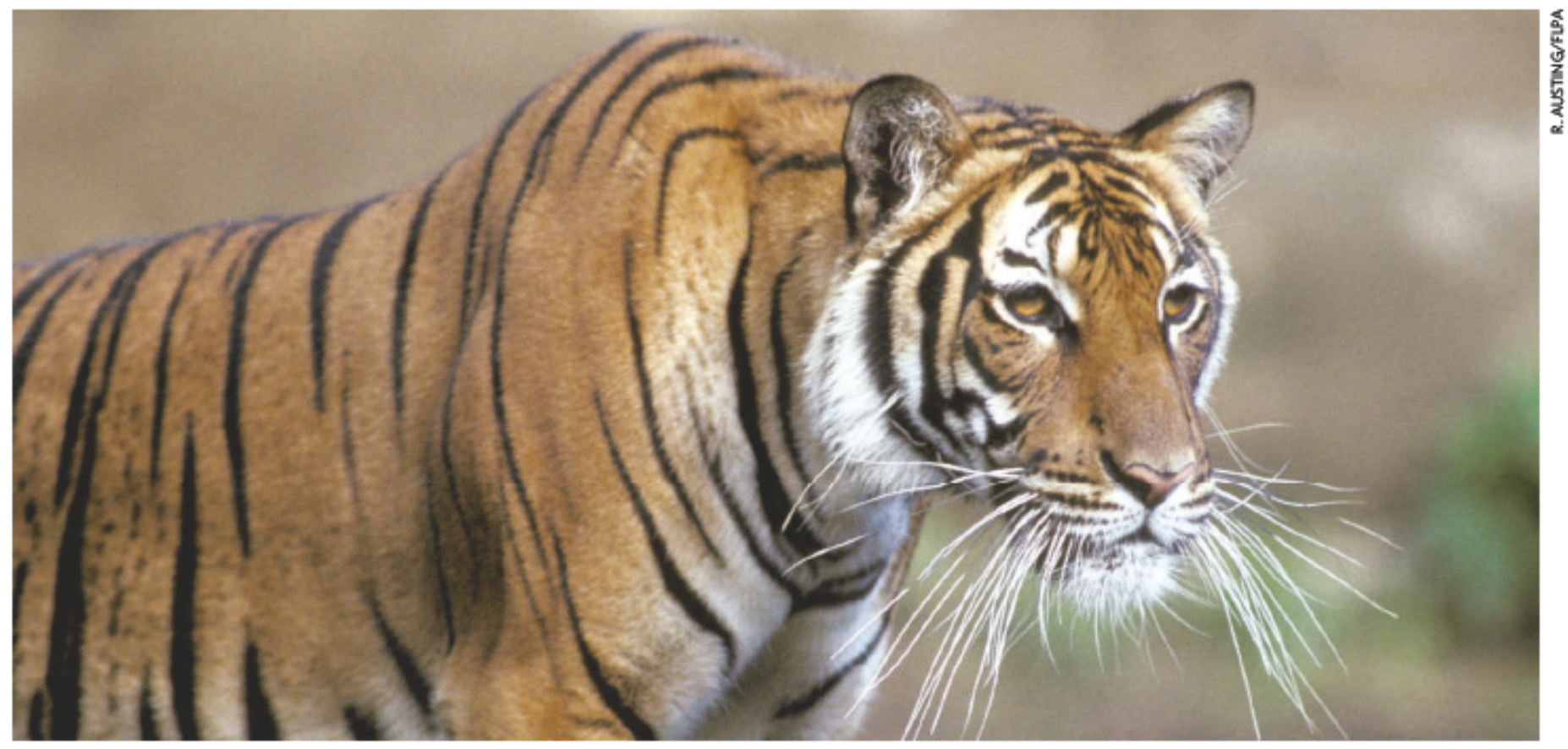

\title{
Doing conservation by numbers
}

\section{NEW YORK}

Tiger conservationists are trying a more business-like approach to saving the threatened species - focusing not on collecting money but on performance standards.

Biologists at the Wildlife Conservation Society (WCS) in New York want to increase the number of tigers (Panthera tigris) at the society's research sites in Asia by $50 \%$ over the next decade. WCS director for science Alan Rabinowitz says the plan, called 'Tigers Forever', will differ from previous conservation attempts because the society's biologists, stationed across Asia, have set targets by which their success can be judged.

In the past, conservation groups have issued pleas for funds to save tigers while often having no clear idea of how that aim should be achieved. It is virtually unprecedented for a group to announce performance targets in advance. "This is not a fund-raising exercise," says Rabinowitz. "We're putting our ass on the line here. Tigers Forever is designed to measure our impact on increasing tiger populations at specific sites."

As well as judging overall success, the information gained about what works and what doesn't in different areas will guide future action. Although conservation groups have made strides in boosting tiger numbers in some areas, particularly India and Russia, "we are not using the lessons learned", says Rabinowitz. Ullas Karanth, an Indian biologist who works with the WCS, adds that "we are trying to be toughminded with our people, seeking rigorous reviews of tiger plans".

That philosophy seems to be attracting donors. Michael Cline, a New York businessman and WCS board member, has contributed to the US $\$ 10$ million already pledged to Tigers Forever. "More organizations should set goals like this," he says. "As a venture capitalist, I believe in fact-based judgements based on likelihood of success."

"I definitely think this will become a trend," adds Sybille Klenzendorf, a biologist who coordinates tiger programmes at the World Wildlife Fund in Washington DC.

From the forests of the Asian subcontinent to the steppes of Russia, poaching, illegal hunting and habitat loss have reduced tiger numbers dramatically in past decades, to between 3,000 and 5,000 animals (see Nature 441, 927-930; 2006). The situation is most critical in the jungles of southeast Asian nations, and the WCS will begin by concentrating on selected reserves there (see 'Wildlife Conservation Society Sites in Asia').

One of the principal goals of the programme is to increase tiger prey. "Tigers eat large, hoofed animals," says Karanth. "The key to saving tigers is to maintain proper prey density."

WCS biologists in Mondulkiri are relatively optimistic despite the low tiger numbers. Prey species have been dramatically reduced by poaching, owing to the many guns available after years of war. But good habitat remains for both prey and tiger. To bring back the prey species, the WCS is encouraging local agencies and governments to set up a variety of incentive-based actions to cut poaching. These include paying informers to expose illegal hunting, offering bounties for guns or tiger traps, and instituting bonuses for diligent rangers.

${ }^{\alpha}$ These are not nice things that people want to hear about," says Rabinowitz. But he says that measures such as the number of traps turned in or the number of poachers identified " are really good surrogates to show how much better things are".

Rex Dalton 